\title{
Analysing underlying Cognitive Process in Reading and Spelling among Dyslexic Students
}

\author{
Lajwanti Motilal Jethwani $^{\# 1}$, Dr. R. Subhashini ${ }^{* 2}$ \\ ${ }^{1}$ Ph. D. Scholar, Department of Psychology, Bharathiar University, Tamil Nadu, India \\ ${ }^{2}$ Dean SF, Former HOD and Associate Professor, Department of Counselling Psychology, \\ Madras School of Social Works, Chennai, India
}

\begin{abstract}
The idea of individual's study is one of the major considerations of the modern theories in education. The aim of this study is to analyse underlying cognitive process in reading and spelling among dyslexic students, over a sample of 60 children belong to private and government schools in Chennai. Schonell spelling test and Schonell reading test were administered to measure the reading and spelling age. F-test is used to analyse the data and the result indicate that there is significant difference in actual age between reading and spelling age.
\end{abstract}

Keywords — Dyslexic; Spelling; Cognitive; Reading

\section{Introduction}

Education is the knowledge, skill, and understanding that individual attain through an educational system for individual's success in almost all spheres of life. The purpose of education is to mould an individual to function effectively as a social being and a useful citizen. It helps to develop that potential to the fullest, enabling him/her to achieve human excellence (Philip, Susan \&Anu, 2002). In today's competitive world, education is a necessity for a person next to food, clothing, and shelter. It is only through education that desired change in the society and upliftment of the poor can take place, without education a person is incomplete. Development and progress of the society depends on the educated people and problems in education could hamper the advancement of the society. Hence, Government should seriously address all the issues that hinder the educational aspects of the country with all sorts of financial and non-financial support. In a nutshell, education is just not the backbone of an individual but of the country and society.

\section{Types and Degrees of Specific Learning disorder}

Specific learning disorder can affect one or more of the following academic domains: reading (coding 315.00), as in the case of dyslexia, written expression (coding 315.2), and/or mathematics (coding 315.1), as in case of dyscalculia (American Psychiatric Association, 2013). In addition, the disorder is classified by severity. The disorder is considered to be "mild" if a student has some learning complexities, but is able to function well with minimal appropriate support services. If a student's learning difficulties need multiple stages of intense, specialized training in order to get proficiency in academic skills. If learning difficulties are so marked, the student is not capable to obtain the essential academic skills without continuous, intensive, specialized training.

\section{Specific Reading Disorder}

The main trait of this disorder is a precise, significant and impairment in the growth of reading skills, which is not exclusively accounted for by mental age, visual insight problems, or poor schooling. Reading comprehension ability, reading word recognition, verbal reading ability, and performance of errands requiring reading may all be affected. Spelling difficulties are often connected with specific reading chaos and often stay into adolescence even after some development in reading has been made. Children with specific reading disorder frequently have a history of specific developmental disorders of speech and language, and comprehensive assessment of current language functioning often reveals subtle contemporaneous difficulties. The condition is found in all known languages, but there is uncertainty as to whether or not its frequency is affected by the nature of the language and of the written script. (Shaywitz SE, Shaywitz BA, 2003)

\section{Diagnostic Guidelines}

The child's presentation should be considerably below the point expected on the basis of age, general aptitude, and school placement. Performance is best assessed by means of an individually administered, standardized test of reading accuracy and comprehension. The precise nature of the reading difficulty depends on the predictable level of reading, and on the language and script. However, in the beginning stages of learning an alphabetic script, there may be complexity in narrating the alphabet, in giving the right names of letters, in giving easy rhymes for words, and in analysing sounds. 
Errors in oral reading skills are listed by,

(a) Lapses, substitutions and distortions of words.

(b) Slow reading rate.

(c) False starts, extended hesitations and imprecise phrasing and

(d) Reversals of words in sentences or of letters within words.

Some deficits in interpretation comprehension, as shown by example,

(e) An inability to recall facts read;

(f) Incapability to draw inferences from material interpret; and

(g) Use of general knowledge as background information rather than of information from a particular story to answer questions about a story read (Melinda TW, 2012).

Specific developmental disorders of reading are generally preceded by a record of disorders in language development. In other cases, children may pass language milestones at the normal age but have difficulties in auditory processing as shown by problems in sound categorization, in rhyming, and possibly by shortfalls in speech discrimination, aural sequential memory and aural association. In some cases, too, there may be problems in visual processing (such as in letter discrimination); however, these are common among children who are just beginning to learn to read and hence are probably not directly causally related to the poor reading. Difficulties in attention, often associated with over activity and impulsivity, are also common (Saroj S, 1982). The precise pattern of developmental difficulties in the preschool period varies considerably from child to child, as does their severity; nevertheless such difficulties are usually (but not invariably) present. Associated emotional and/or behavioral disturbances are also common during the school-age period. Emotional problems are more regular during school years, but hyperactivity syndromes are most likely to be present in later childhood and adolescence. Low self-esteem is common and problems in school adjustment and in peer relationships are also frequent.(Michael R, 2012)

\section{Specific Spelling Disorder}

The main element of this disorder is a specific and important impairment in the improvement of spelling skills in absence of a record of specific reading chaos, which is not exclusively accounted for by low mental age, visual insight problems, or poor schooling. The skills to spell orally and to write out words appropriately are both affected. Children whose difficulty is solely one of handwriting should not be incorporated, but in some cases spelling difficulties may be connected with problems in writing. Unlike the common pattern of exact reading disorder, the spelling errors tend to be principally phonetically accurate.

\section{Diagnostic Guidelines}

The child's spelling recital should be considerably below the level predictable on the basis of his or her age, universal intelligence, and school placement, and is best evaluated by means of an independently administered, consistent test of spelling. The child's reading skills should be within the regular series and there should be no record of earlier significant reading intricacy. The difficulties in spelling should not be mainly due to grossly inadequate teaching or to the direct effects of deficits of visual, hearing, or neurological function, and should not obtain a result of any neurological, psychiatric, or other chaos. Although it is known that a "pure" spelling disorder differs from reading disorders associated with spelling difficulties, little is known of the antecedents, course, correlates, or outcome of specific spelling disorders.

\section{Methods} below.

The objective and methods used in this study are listed

\subsection{Objective of the Study}

The objective is to measure cognitive process in reading and spelling among dyslexic students.

Hypothesis - There is significant difference in reading and spelling age among dyslexic students

\subsection{Sampling Method}

The sampling symbolizes a group of dissimilar nonprobability sampling techniques. Also recognized as judgmental, choosy or subjective sampling, purposive sampling relies on the result of the researcher when it comes to choosing the units that are to be studied.

\subsection{Sampling Procedure}

Purposive sampling is the population "non-randomly selected based on a particular characteristic". Purposive non-probability sampling and stratified probability sampling are very related but warn that there is a vital difference between the two. Manoranjini Jeyasekaren (2014) explored the visual, auditory, kinesthetic, tactile techniques on reading level among dyslexic children.

\subsection{Sampling Frame and Sample Size}

Students are selected from mnemonics centre, in this centre various school student register for psychological assessment and remedial enhancement. 90 samples are

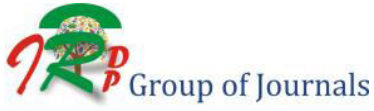


taken for this study with the age of 7 to 8 years, 8 to 10 years and 11 to 12 years.

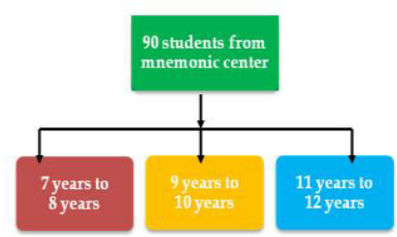

Fig.1: Classification of samples

\subsection{Inclusion Criteria}

- Specific learning disability children's

- Age level between 7 years to 12 years

- Children's are living in Coimbatore to allow the participate in this study

- Students are living with parent and hostel

\subsection{Exclusion Criteria}

- ADHD, MR , Autism, developmental delayed, emotional and behavior issues children

- The children's who living with guardians or grandparents comes under the exclusion criteria

- The students who discontinue their studies comes under the exclusion criteria

- The Remedial training participate students particular district only other district children's comes under the exclusion criteria

\subsection{Tools}

The following psychological tools were used to collect the necessary data. They were;

- Schonell: gradedword reading test developed by Schonell and GoodAcre (1971)

- Schonell: gradedword spelling test developed by Schonell and GoodAcre (1971)

\subsection{Questionnaire I :Schonell: Graded Word Reading Test}

Schonell grade word reading test develop by Schonell and Goodacre (1971). It was used to test the reading age of children age between 6to 12 years 6 month. It consists of 100 words. The reliability and validity of schonell: graded word reading 0.73 and 0.85 respectively.

\subsection{Questionnaire II :Schonell : Graded Word Spelling Test}

Schonell grade spelling test developed by Schonell and Goodacre (1971). The purpose of this test, used to measure the spelling age of children between 6 to 12 years 6 month. The reliability and validity of Schonell graded spelling 0.69 and 0.83 respectively.

\section{Result and Discussion}

Table 1: Gender, class and age wise distribution of the sample

\begin{tabular}{|l|l|l|c|c|}
\hline \multirow{2}{*}{ S.No. } & \multirow{2}{*}{ Variables } & Conditions & Frequency & Percentage \\
\hline \multirow{2}{*}{1} & \multirow{2}{*}{ Gender } & Males & 31 & 52 \\
\cline { 3 - 5 } & & Females & 29 & 37 \\
\hline \multirow{2}{*}{2} & \multirow{2}{*}{$\begin{array}{l}\text { Age } \\
\text { Range }\end{array}$} & 7 to 8 years & 27 & 45 \\
\cline { 3 - 5 } & & 9 to 10 years & 19 & 31.7 \\
\cline { 3 - 5 } & & 11 to 12 years & 14 & 23.3 \\
\hline
\end{tabular}

It is noted from the above table 1 , that there were more male students $(52 \%)$ as against females $(37 \%)$. As of the age wise distribution, $45 \%$ of the sample belonged to 7-8 years (early childhood), $31.7 \%$ belonged to 9 to 10 years (middle childhood) and $23.3 \%$ were in the age range of 11 to 12 years (Adolescence).

Recent analyses about gender difference in SLD research studies revealed that large groups of children in school districts are finding the same percentage of Specific Learning Disabled in girls as in boys. Many psychologist and educators now believe that former studies are flawed because boys are more likely to be referred as a result of behavioral problems. It is also possible that some people still have higher academic expectations for boys than for girls (Stowe, 2000). Hence it is assumed that the above chosen sample would be a true representation of the population and would provide a clear picture for future examination.

Table 2: F-value for reading and spelling age between age group among dyslexic students

\begin{tabular}{|l|l|c|c|c|c|c|}
\hline & \multicolumn{1}{|c|}{ Age } & $\begin{array}{c}\text { Sum of } \\
\text { Squares }\end{array}$ & Df & $\begin{array}{c}\text { Mean } \\
\text { Square }\end{array}$ & F & Sig. \\
\hline $\begin{array}{l}\text { Spelling } \\
\text { Age }\end{array}$ & $\begin{array}{l}\text { Between } \\
\text { Groups }\end{array}$ & 80.722 & 2 & 40.361 & 86.545 & .000 \\
\cline { 2 - 7 } & $\begin{array}{l}\text { Within } \\
\text { Groups }\end{array}$ & 26.583 & 57 & .466 & & \\
\cline { 2 - 7 } & Total & 107.305 & 59 & & & \\
\hline \multirow{2}{*}{$\begin{array}{l}\text { Reading } \\
\text { Age }\end{array}$} & $\begin{array}{l}\text { Between } \\
\text { Groups }\end{array}$ & 84.202 & 2 & 42.101 & 77.734 & .000 \\
\cline { 2 - 7 } & $\begin{array}{l}\text { Within } \\
\text { Groups }\end{array}$ & 30.871 & 57 & .542 & & \\
\cline { 2 - 7 } & Total & 115.074 & 59 & & & \\
\hline
\end{tabular}

Table 2 shows that significant difference age group among dyslexic students. The calculated F-value for which is less than table value of at 0.001 level. It is inferred that

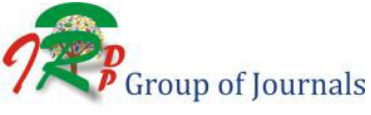


there was statistically significant difference found in the actual age and reading and spelling age.

The results suggest that the students with actual age has difference in spelling and reading age may probably be at risk for academic failure in the future Early identification of cognitive deficit may be essential for early intervention in order to anticipate and improve future academic and Cognitive deficits. We could propose a cognitive- based approach to enhance cognitive performance of children with SLD. The study concludes that SLD is a major problem which hinders the educational success of students and if intervened at the right time, SLD can be overcome.

\section{Limitation of the Study}

- Since the present study was experimental in nature, the size of the sample selection is limited. Hence, generalization of the results cannot be made.

- The Students with SLD and Students without SLD who study English medium only in Coimbatore area are considered for this study.

A demographic comparison between the groups as well as the influence of the outcome has not been considered which presents future avenues for research.

\section{Suggestions and Recommendations}

The present research would help the Special educator, Psychologist and main stream teachers to identify the students with Specific Learning Disabilities (SLD) and make out their cognitive Deficit and how to overcome through cognitive remedial training.

- The present study would suggest enhancing the cognitive abilities and academic skills like reading, spelling, writing skills of SLD in Learning of Pass Reading Enhancement Training.

- The study would provide concrete suggestions to psychologists, special educators, teachers, parents, Heads of the institutions and government organizations regarding with the steps to be taken for academic excellence of SLD.

\section{References}

[1] Michael R. Social And Emotional Problems Related To Dyslexia. retrieved from the International Dyslexia Association on May 31, 2012. Available at: http://www.interdys.org/ewebeditpro5/ upload/ socialemotionproblemsrelatedtodyslexia.pdf

[2] Saroj S. Multisensory Approach to the Teaching of Reading to Learning Disabled Students: A Review of Research and A Case Study. retrieved from Research Review Series (1982) on November 19, 2011. Available at: http://catalogue.nla.gov.au/record/5442521

[3] Melinda Tw. Dyslexia More Common In Boys Abc News (2012). retrieved on November 15, 2011. Available at: http://abcnews. go.com/health/story?id=117122\&page=1\#.uk7t_equtf0 shaywitz se, shaywitz ba. dyslexia (specific reading disability). pediatr rev 2003;24(5):147-52

[4] Daniel S. Cipp Model Of Evaluation. Journal of Higher Education Outreach and Engagement 2011.

[5] Jeyasekaran Jm. Effectiveness of Visual Auditory Kinesthetic Tactile Technique on Reading Level Among Children with Dyslexia at Helikx Open School And Learning Centre, Salem. Int J Med Sci Public Health 2014;4:315-318. 